Revista Complutense de Educación

ISSNe: 1988-2793

https://dx.doi.org/10.5209/rced.65076

\title{
Formación continua
}

Coordinador: Antonio Bernal Guerrero

Autores: Carolina Fernández-Salinero de Miguel y Pilar Pineda Herrero

Editorial: Síntesis

Año de publicación: 2019

$N^{\circ}$ de páginas: 216

ISBN: 978-84-917185-1-2

\section{Análisis}

Palabras clave: Formación continua, Organización y planificación de la Formación continua, Modalidades y enfoques metodológicos, Identidad profesional, Formación profesional dual, Evaluación de la formación continua.

Biografía del autor-coordinador: Antonio Bernal Guerrero es Catedrático de Universidad en la Facultad de Ciencias de la Educación (Universidad de Sevilla) en el departamento de Teoría e Historia de la Educación y Pedagogía Social. Responsable del Grupo de Investigación HUM403: Investigación Pedagógica de la Persona. Especialista en Teoría de la Educación, formación del profesorado, identidad personal y educación emprendedora.

Fuentes bibliográficas: Al final del libro se recoge una selección de referencias bibliográficas relacionadas con la formación continua, teniendo en cuenta tanto bibliografía básica de la temática como trabajos que abordan la realidad actual y las necesidades formativas. Las referencias presentadas constituyen la base de la planificación, el diseño y la evaluación de la formación, las estrategias, las metodologías y los programas para mejorarla, así como las competencias de los formadores en las organizaciones, tomando como punto de referencia el ámbito europeo. A la bibliografía completa se accede a través de la web de la propia Editorial Síntesis.

Descripción de la obra: Este libro comienza con un prólogo que pretende adentrarnos en la importancia y relevancia de la formación continua. Seguidamente, se estructura en 6 capítulos que siguen un recorrido exhaustivo y completo por el contenido, persiguiendo evidenciar ideas y propuestas que mejoren los procesos formativos en las organizaciones y atendiendo a su carácter de continuidad. Además, y como complemento al contenido estructurado en capítulos, se presentan al final de cada uno de ellos, un apartado de conclusiones que clarifica la idea que los autores pretenden trasmitir, haciendo reflexionar a su vez al lector.

Podemos estructurar esta obra en tres bloques principalmente.

El primero de ellos (capítulos 1, 2 y 3) comienza por la conceptualización de la formación continua, recogiendo el contexto europeo, los organismos internacionales referentes y el paso de la educación continua al aprendizaje a lo largo de la 
vida. Además, se abordan los cambios socioculturales y laborales, el horizonte de la formación continua y su institucionalización, atendiendo a la lógica organizativa y la formación, las políticas públicas en España y Europa y las tendencias formativas en las organizaciones. Finalmente, se exponen las modalidades y enfoques metodológicos en la formación continua, tanto a nivel presencial como mediado por las TIC.

El segundo bloque (capítulo 5) destaca la relevancia de los perfiles profesionales de los responsables de la formación continua, es decir, sus funciones, roles y competencias, la formación que poseen y los espacios de intervención, incluyendo la formación profesional dual.

El tercer bloque (capítulos 4 y 6) hace referencia al diseño, implantación y evaluación de la formación continua. Para ello se exponen los principios y orientaciones teóricas, las necesidades formativas, los objetivos, contenidos y estrategias formativas, los recursos, la implementación del programa, la importancia de la planificación de la formación continua, los modelos de evaluación y su transferencia.

Método y estilo: La obra se estructura de manera clara, sencilla y práctica, cumpliendo al mismo tiempo las funciones de referente teórico y manual para la práctica educativa, sin dejar de lado el rigor que caracteriza a un texto académico. La elaboración del libro por parte de tres investigadores especialistas en formación continua, pertenecientes a distintas universidades españolas, aporta al mismo un valor añadido, puesto que trasciende las barreras de la experiencia individual y local.

Resumen: El libro comienza con un prólogo que pone su énfasis en la necesidad de conceptualizar y caracterizar la educación como un proceso continuo, no solo ligado a las etapas vitales de los individuos, sino también condicionada por un determinado contexto social, económico y cultural que se encuentra en constante cambio y que determinará la formación que se recibe. De esta manera, las organizaciones y las empresas deben tener en cuenta las necesidades del entorno para responder a ellas, planificando estrategias formativas para la vida profesional y laboral.

\section{Juicio Crítico}

A nivel teórico esta obra nos ofrece un idóneo marco de referencia y de comprensión desde el cual abordar la formación continua, atendiendo al cambiante contexto social, económico y cultural en el que nos encontramos inmersos. Sus autores han conseguido aunar sus esfuerzos en docencia e investigación para ofrecer un libro interesante, tanto a nivel teórico como práctico.

A nivel teórico nos aclara con precisión el origen de la formación continua en los años sesenta, ligada al concepto de aprendizaje a lo largo de la vida y su vinculación hoy día a los cambios del contexto sociolaboral. Se presenta su evolución y recorrido bajo el marco institucional español y europeo, ofreciendo el panorama de las actuaciones llevadas a cabo hasta el momento y de las modalidades y enfoques utilizados. Se destaca a su vez las ventajas e inconvenientes de la utilización de estos y el papel fundamental que desempeñan los agentes implicados en la formación continua. 
Con respecto a su aporte práctico y a raíz de las necesidades encontradas, esta obra ofrece, desde una perspectiva pedagógica, un conjunto de objetivos, contenidos, estrategias y recursos para el diseño y la implementación de un modelo de formación continua. Se ofrecen a su vez, una amplia gama de modelos de evaluación que ayudan a mejorar su impacto, su fortalecimiento y su transferencia.

Es de resaltar como aspecto positivo, la inclusión de un apartado de conclusiones al finalizar cada capítulo que ayuda a ir sintetizando las distintas aportaciones al ámbito de la formación continua que nos pretenden hacer llegar sus autores, haciendo pequeñas paradas para reflexionar sin necesidad de esperar al final de la obra.

Sintéticamente, esta obra viene a llenar un espacio de interés académico y profesional, necesitado de aportaciones sustantivas que fortalezcan las posibilidades de desarrollo y consolidación de la formación continua.

Ángela Martín-Gutiérrez Facultad de Ciencias de la Educación

Universidad de Sevilla 